\title{
Adsorption of phosphate in water on a novel calcium hydroxide-coated dairy manure-derived biochar
}

\author{
Yong-Keun Choi ${ }^{1,2}$, Hyun Min Jang1, Eunsung $\operatorname{Kan}^{1,2^{\dagger}}$, Anna Rose Wallace ${ }^{3}$, Wenjie Sun ${ }^{3}$ \\ ${ }^{1}$ Texas A\&M Agrilife Research Center, Stephenville, TX 76401, USA \\ ${ }^{2}$ Office of Sponsored Projects, Tarleton State University, Stephenville, TX 76401, USA \\ ${ }^{3}$ Department of Civil and Environmental Engineering, Southern Methodist University, Dallas, TX 75205, USA
}

\begin{abstract}
The present study investigated a novel calcium hydroxide-coated dairy manure-derived biochar (Ca-BC) for adsorption of phosphate from water and dairy wastewater. The Ca-BC showed much higher adsorption of phosphate than that of dairy manure-derived biochar. The Ca-BC possessed mainly the calcium hydroxide and various functional groups resulting in high reactivity between phosphate and calcium hydroxide in the Ca-BC. The adsorption of phosphate onto $\mathrm{Ca}-\mathrm{BC}$ followed pseudo-second order kinetic and Freundlich isotherm models indicating chemisorptive interaction occurred on energetically heterogeneous surface of Ca-BC. The maximum adsorption capacity of the Ca-BC was higher than those of iron oxide and zinc oxide-coated biochars, but lower than those of $\mathrm{CaO}$ - and $\mathrm{MgO}$-coated biochars. However, the Ca-BC showed high reactivity per surface area for adsorption of phosphate indicating importance of surface functionalization of biochar. On the other hand, the adsorption of phosphate in dairy wastewater on Ca-BC was lower than that in water owing to competition between other anions in wastewater and phosphate. Overall, the $\mathrm{Ca}-\mathrm{BC}$ would be a low cost and effective adsorbent for recovery of phosphate from water and wastewater.
\end{abstract}

Keywords: Adsorption, Biochar, Calcium hydroxide-coated biochar, Dairy wastewater, Phosphate

\section{Introduction}

Use of phosphate for agricultural systems has increased with growing demand of food production over the past decades [1, 2] However, when excessive phosphate in wastewater and agricultural systems is not properly treated and released to various water bodies, it often causes serious algal blooms and eutrophication in water [3, 4]. In contrast, there has been increasing demand for recovery of phosphate from wastewater and agricultural run-off since the major sources of phosphate fertilizers have been limited [4-6]. Thus, effective removal and recovery of phosphate from various wastewater and agricultural run-off is an urgent need to be developed.

Various methods for removal of phosphate from wastewater have been explored, including biological method, chemical precipitation, electrochemical process, coagulation, membrane separation, and adsorption [7-11]. Biological phosphate uptake often fluctuates with operating and growth conditions [4] while chemical precipitation and coagulation are hindered by their high chem- ical consumption, low recovery efficiency, and excessive production of chemical sludge [5]. Electrochemical process is restricted by limited capacity for wastewater treatment containing multiple anionic compounds and the need to replace electrodes frequently [6, 7].

Recently adsorption of phosphate on biochar has received increasing attention as biochar could be a low-cost and effective adsorbent for removal of phosphate in water and wastewater [12-19]. To date the biochar-based adsorption of phosphate has used the raw and metal oxide-coated biochars derived from lignocellulose biomass [11, 19-24]. The raw biochars from various lignocellulosic biomass have shown limited adsorption capacities for phosphate due to lack of effective interactions with phosphate $[3,19]$. On the other hand, the metal oxide-coated lignocellulose-derived biochars such as $\mathrm{CaO}$ and MgO-coated biochars revealed high adsorption capacities of phosphate (i.e., 1-110 mg phosphate per g of biochar) (Table 1) [22-29]. For instance, Liu et al. [22] reported the high adsorption of phosphate on Ca-impregnated ramie-derived biochar while Fang et al. [30] found the
This is an Open Access article distributed under the terms of the Creative Commons Attribution Non-Commercial License (http://creativecommons.org/licenses/by-nc/3.0/) which permits unrestricted non-commercial use, distribution, and reproduction in any medium, provided the original work is properly cited.

Copyright (C) 2019 Korean Society of Environmental Engineers
Received August 16, 2018 Accepted October 24, 2018

${ }^{\dagger}$ Corresponding author

Email: eunsung.kan@ag.tamu.edu

Tel: +1-254-968-4144 Fax: +1-254-968-3759

ORCID: 0000-0001-6298-6096 
Table 1. Removal of Phosphate in Water Using Metal-coated Biochars Derived from Various Feedstocks

\begin{tabular}{|c|c|c|c|c|c|}
\hline Feedstocks [Ref.] & Pyrolysis conditions & Metals on biochar & $\begin{array}{l}\text { Max. adsorption } \\
\text { (mg P/g biochar) }\end{array}$ & $\begin{array}{l}\text { Adsorption/area } \\
\text { (mg P/m } / \mathrm{m}^{2} \text { biochar) }\end{array}$ & $\begin{array}{l}\text { Adsorption } \\
\text { isotherm }\end{array}$ \\
\hline Reed grass [25] & $600^{\circ} \mathrm{C}, 1 \mathrm{~h}$ & Magnesium oxide & 110 & 0.64 & Langmuir \\
\hline Wood chips [26] & $500^{\circ} \mathrm{C}, 2 \mathrm{~h}$ & Iron oxide & 3.2 & 0.29 & Langmuir \\
\hline Orange peel [23] & $700^{\circ} \mathrm{C}, 6 \mathrm{~h}$ & Iron oxide & 1.2 & 0.06 & Langmuir \\
\hline Bamboo [24] & $400^{\circ} \mathrm{C}, 1 \mathrm{~h}$ & Montmorillonite & 105 & 5.3 & Redlich-Peterson \\
\hline Coir pith [27] & $700^{\circ} \mathrm{C},-$ & Zn oxide & 5.1 & - & Langmuir \\
\hline Ramie stem [22] & $500^{\circ} \mathrm{C}, 2 \mathrm{~h}$ & Calcium oxide & 105 & 7 & Langmuir \\
\hline Bamboo [28] & - & Iron oxide & 4.1 & - & Freundlich \\
\hline Crab shell [29] & $600^{\circ} \mathrm{C}, 2 \mathrm{~h}$ & Calcite & - & - & - \\
\hline Dairy manure [this study] & $\begin{array}{l}\text { Impregnation of } \mathrm{Ca} \text { at } \\
\text { ambient condition }\end{array}$ & Calcium hydroxide & 13.6 & 4.9 & Freundlich \\
\hline
\end{tabular}

efficient adsorption of phosphate on Ca-Mg loaded corncob-derived biochar. Dai et al. [29] also showed the high phosphate adsorption of calcite-rich biochar made from crab shells. Despite high adsorption capacities of $\mathrm{CaO}$ - and calcite-coated biochar for phosphate, the preparation of these biochars required high energy for pyrolysis and calcination at high temperature [22, 29, 30].

To the best of our knowledge, this is the first report to use a calcium hydroxide-coated dairy manure-derived biochar (Ca-BC) for effective adsorption of phosphate from dairy wastewater. This study used the dairy manure-derived biochar (raw BC) for adsorption of phosphate in water while most of raw BC have been used for removal of heavy metals, ions and pesticides [31, 32]. Others' studies prepared the $\mathrm{CaO}$ - and calcite-coated lignocellulose-derived biochar using high energy-consuming processes such as pyrolysis or calcination of calcium-impregnated biochar at $500-900^{\circ} \mathrm{C}[22,29]$. However, in this study the Ca-BC was prepared by the low energy-consuming processes combining wet impregnation of calcium ions to biochar at ambient temperature followed by mild drying of biochar (please see the methods section for the detailed procedures).

Thus, this study presents the physical and chemical properties of Ca-BC and its adsorption characteristics via adsorption isotherm and kinetic models. Possible mechanisms associated with the adsorption of phosphate on the Ca-BC are addressed. Furthermore, the adsorption of phosphate in real dairy effluents on the Ca-BC was conducted to understand the impact of wastewater components on the adsorption efficiency of phosphate.

\section{Materials and Methods}

\subsection{Biochar and Chemicals}

The raw BC was obtained from Professor Sergio Capareda at Texas A\&M University (College Station, TX). As described by Nam et al. [33], it was produced by gasification of dairy manure at $500^{\circ} \mathrm{C}$. $\mathrm{K}_{2} \mathrm{HPO}_{4}, \mathrm{CaCl}_{2}, \mathrm{Ca}(\mathrm{OH})_{2}, \mathrm{CaO}$, and $\mathrm{SiO}_{2}$ were purchased from
Sigma-Aldrich (St. Louis, MO, USA) [33]. The Hach kits for phosphate measurement were purchased from Hach Inc. (Loveland, CO, USA).

\subsection{Preparation and Characterization of $\mathrm{Ca}-\mathrm{BC}$}

The Ca-BC was prepared by using the method modified from those for coating of iron onto biochar and activated carbon at ambient conditions as Kan and Huling [34] and Samsuri et al. [35] reported. For impregnation of calcium ions onto raw $\mathrm{BC}$ under ambient conditions, $20 \mathrm{~g}$ of raw $\mathrm{BC}$ was stirred with $400 \mathrm{~mL}$ of $2 \mathrm{M} \mathrm{CaCl}_{2}$ solution for $1 \mathrm{~d}$ at $25^{\circ} \mathrm{C}$. While the calcium ions from $\mathrm{CaCl}_{2}$ solution were fully mixed with the raw $\mathrm{BC}$, they were reacted with the hydroxyl groups of raw $\mathrm{BC}$ to make calcium hydroxide on the raw $\mathrm{BC}$ as seen in Eq. (1):

$$
\begin{gathered}
\mathrm{Ca}^{2+} \text { (aq.) }+\mathrm{OH} \text { groups on the raw } \mathrm{BC} \leftrightarrow \\
\mathrm{Ca}(\mathrm{OH})_{2} \text { (s.) on the Ca-BC }
\end{gathered}
$$

After that, the raw BC coated with calcium hydroxide was separated by centrifugation (x 4,000 g, $30 \mathrm{~min}$ ) and placed to an oven for drying at $105^{\circ} \mathrm{C}$ for $12 \mathrm{~h}$.

The scanning electron microscopy (SEM) images were obtained with Hitachi HT7700 field emission scanning electron microscope $(10 \mathrm{kV})$. Powder X-ray diffraction (XRD) patterns of the powered sample were performed on a Bruker D8 Discover (Bruker, Billerica, MA, USA) with a $\mathrm{Cu} \mathrm{K} \alpha$ radiation source. The measurement of specific surface area was performed using a Quantachrome NOVA 2000e Surface Area and Pore Size Analyzer (BET). For each analysis, 0.1 to $0.5 \mathrm{~g}$ of dry sample was placed in a bulb cell under the parameters described in the manual instruction. The elemental analysis of dairy manure and raw BC were conducted by Robertson Microlit Laboratories (Ledgewood, New Jersey).

The values of $\mathrm{pH}$ at point of zero charge $(\mathrm{pH}, \mathrm{pzc})$ for the raw $\mathrm{BC}$ and the Ca-BC were determined using a modified method described in previous study [36]. $0.2 \mathrm{~g}$ of dry biochar sample and $20 \mathrm{~mL}$ of $0.1 \mathrm{M} \mathrm{KCl}$ solution were mixed in different $50 \mathrm{~mL}$ 
polypropylene centrifuge tubes. The initial $\mathrm{pH}$ of the mixture solution was adjusted to the range of 1.2-10 using either $1 \mathrm{M}$ $\mathrm{HCl}$ or $1 \mathrm{M} \mathrm{NaOH}$ solutions. Each tube was vigorously agitated in a shaker for $24 \mathrm{~h}$ at ambient room temperature. After that, the suspensions were settled down and the final $\mathrm{pH}$ was measured immediately. The differences between final and initial $\mathrm{pH}$ values $(\Delta \mathrm{pH})$ were calcuted and plotted against the initial $\mathrm{pH}$ values. Therefore, the initial $\mathrm{pH}$ at which $\Delta \mathrm{pH}$ is zero is the $\mathrm{pH}$, pzc.

The surface functional groups of biochar samples were examined with a Bruker Vertex 70 Fourier-transform infrared spectroscopy (FT-IR) using the DRIFTS method. A dry biochar was ground to a fine powder in a mortar and pestle. Approximately $20 \mathrm{mg}$ of the powdered sample was mixed with $45 \mathrm{~g}$ potassium bromide $(\mathrm{KBr})$ and then transferred to a small vessel and placed in the instrument. A $\mathrm{KBr}$ background was analyzed prior to sample analysis. Each sample was scanned 1,200 times to minimize sample noise. Wavenumber was measured in the range from 600 to $4,000 \mathrm{~cm}^{-1}$. The samples were analyzed five times and the average of the five analyses was used as the result. The instrument was purged with $\mathrm{CO}_{2}$-free air from a $\mathrm{CO}_{2}$ adsorber for $30 \mathrm{~min}$ between each analysis. All experiments were carried out at least in triplicate.

To analyze leaching of cations from the biochars, $0.1 \mathrm{~g}$ of raw $\mathrm{BC}$ or Ca-BC were added to $0.02 \mathrm{~L}$ of $\mathrm{DI}$ water at ambient $\mathrm{pH}$ and stirred at $150 \mathrm{rpm}$ for $72 \mathrm{~h}$. Various cations such as $\mathrm{Ca}, \mathrm{Mg}$ and $\mathrm{Fe}$ ions in the leachate solution were analyzed using an ion chromatograph (IC) (Dionex Aquion, Thermo scientific, MA, USA). In addition, the leachate solutions containing the cations from raw BC and Ca-BC were stirred with the phosphate solution under the same conditions as the above adsorption experiments (initial phosphate of $30 \mathrm{ppm}$, ambient $\mathrm{pH}, 150 \mathrm{rpm}$, $72 \mathrm{~h}$ ). The removal of phosphate in the leachate solution after $72 \mathrm{~h}$ was evaluated and indicated any possible reactions between phosphate and cations in water during the adsorption experiments.

\subsection{Adsorption of Phosphate in Water onto Raw BC and Ca-BC}

The phosphate adsorption capacities of the raw $\mathrm{BC}$ and the Ca-BC were evaluated by vigorously stirring $0.1 \mathrm{~g}$ biochar with $0.02 \mathrm{~L}$ of $30 \mathrm{mg} / \mathrm{L}$ phosphate in a DI water without any $\mathrm{pH}$ adjustment (initial pH of 8.5) for $72 \mathrm{~h}$. After $72 \mathrm{~h}$ adsorption, the aqueous samples were used for measuring phosphate concentration after centrifuging the slurry samples from the flasks with each biochar. The adsorption experiments were conducted at least in triplicate.

\subsection{Effects of Solution pH on Adsorption of Phosphate onto Ca-BC}

The effects of solution $\mathrm{pH}$ on adsorption of phosphate were also investigated by vigorously mixing $0.1 \mathrm{~g}$ biochar with $0.02 \mathrm{~L}$ of $30 \mathrm{mg} / \mathrm{L}$ phosphate in a DI water with the initial $\mathrm{pH}$ of solution from 3 to 8.5 for $72 \mathrm{~h}$. The adsorption experiments for $\mathrm{pH}$ effect were conducted at least in triplicate.

\subsection{Adsorption Isotherms and Kinetics Experiments}

The batch experiments for adsorption isotherm were conducted by suspending 5-400 $\mathrm{mg}$ of the Ca-BC in a series of flasks containing $0.02 \mathrm{~L}$ of $30 \mathrm{mg} / \mathrm{L}$ phosphate solutions in a DI water at $20^{\circ} \mathrm{C}$. The initial $\mathrm{pH}$ of phosphate solution with the Ca-BC ( $\mathrm{pH}$ of 8.5) was not adjusted during the adsorption experiments. The adsorption experiments were carried out by shaking at the constant speed $(200 \mathrm{rpm})$ at $20^{\circ} \mathrm{C}$ for $72 \mathrm{~h}$ to ensure equilibrium was reached. The post-adsorption phosphate solution was sampled after equilibrium in replicate and analyzed. The differences between initial and final concentrations were used to calculate the mass of phosphate adsorbed to the Ca-BC. The Langmuir, Freundlich and Temkin isotherm models were used to interpret the isotherm experimental data.

The adsorption kinetics was also investigated by vigorously stirring $0.1 \mathrm{~g}$ of the Ca-BC and $0.02 \mathrm{~L}$ of $30 \mathrm{mg} / \mathrm{L}$ phosphate solution at $\mathrm{pH} 8.5$ at $20^{\circ} \mathrm{C}$. The aqueous samples were taken at a regular interval for $6 \mathrm{~h}$. The experimental results were fitted to the adsorption kinetic models including pseudo-first order, pseudo-second order, Elovich models.

A trial and error procedure were performed using the solver function in Microsoft Excel to minimize the sum of squared errors which was the sum of squared errors (SSE, (q, measured - q, calculated $\left.)^{2}\right)$. In addition, Chi-square $\left(\chi^{2}\right.$, the sum of the squares of the differences between measured data $\left(\mathrm{q}_{\mathrm{m}}\right)$ and calculated data $\left(\mathrm{q}_{\mathrm{c}}\right)$ ) was also calculated by Eq. (2) [37].

$$
\chi^{2}=\sum \frac{\left(q_{m}-q_{c}\right)^{2}}{q_{c}}
$$

Mathematical equations of adsorption isotherms and kinetics models were listed in Table S1.

\subsection{Adsorption of Phosphate onto Ca-BC in Real Dairy Wastewater}

The lagoon effluents from the dairy farm at Southwest Dairy Research Center at Tarleton State University in Stephenville, Texas (Tarleton dairy farm, hereafter) were taken and fed to the glass flaks containing the Ca-BC to figure adsorption of phosphate, chemical oxygen demand (COD) and total nitrogen. The adsorption of total phosphate, total nitrogen and COD onto the Ca-BC were investigated at ambient conditions by stirring $0.1 \mathrm{~g}$ Ca-BC and $20 \mathrm{~mL}$ dairy wastewater in $50 \mathrm{~mL}$ flasks for $72 \mathrm{~h}$. The adsorption experiments were conducted at least in triplicate. Also, various cations such as $\mathrm{Ca}, \mathrm{Mg}$ and $\mathrm{Fe}$ ions and anions such as sulfate, chloride, nitrate, and fluoride in the real dairy wastewater were analyzed using an IC.

\subsection{Analytical Methods}

The liquid samples from adsorption experiments were filtered through $0.22 \mu \mathrm{m}$ membrane. Total nitrogen, total phosphate and COD were analyzed by using Hack kits (Loveland, CO, USA).

The removal efficiency (RE\%) of phosphate in water was evaluated by using Eq. (3): 


$$
R E \%=\frac{\begin{array}{c}
\text { Initial concentration of phosphate in water }- \\
\text { final concentration of phosphate in water })
\end{array}}{\text { Initial concentration of phosphate }} \times 100
$$

The adsorption capacity (Q) for phosphate was also calculated by Eq. (4):

(Inital concentration of phosphate in water - final $Q=\frac{\text { concentration of phosphate in water }) \times \text { volume of water }}{\text { amount of biochar }}$

(Q: mg of phosphate adsorbed onto the biochar, initial concentration of phosphate: $\mathrm{mg}$ of $\mathrm{P}$ per $\mathrm{L}$ of solution at $\mathrm{t}=\mathrm{t}_{0}$, final concentration of phosphate: $\mathrm{mg}$ of $\mathrm{P}$ per $\mathrm{L}$ of solution at $\mathrm{t}=\mathrm{t}_{\mathrm{f}}$ )

\section{Results and Discussion}

\subsection{Preparation and Characterization of $\mathrm{Ca}-\mathrm{BC}$}

The SEM images of raw BC and Ca-BC present the structures of these biochars, respectively (Fig. S1). The images exhibited that the Ca-BC had the calcium aggregates deposited on the surface of biochar while the raw BC showed mostly the irregular pores with different sizes and little aggregates. The EDX analysis of Ca-BC revealed strong peak for Ca compared with the raw BC ensuring the presence of abundant calcium on the surface of Ca-BC (Table S2). The XRD patterns of Ca-BC showed that the diffraction peaks at $2 \theta=26,50$ (for $\mathrm{SiO}_{2}$ ), 33, 46 (for calcium hydroxide $\left(\mathrm{Ca}(\mathrm{OH})_{2}\right.$ ), and 54, 64 (for $\mathrm{CaO}$ ) in Fig. 1. The major peak at $2 \theta=33$ in Fig. 1 indicated the calcium hydroxide was dominated in the Ca-BC compared with that in the raw BC which would play a key role for enhancing adsorption of phosphate via surface complexation. Fig. 2(a) shows the FT-IR analysis of raw $\mathrm{BC}$ and $\mathrm{Ca}-\mathrm{BC}$. Both raw $\mathrm{BC}$ and $\mathrm{Ca}-\mathrm{BC}$ had Si-O-Si stretching (452 $\left.\mathrm{cm}^{-1}\right)$, C-O stretching vibration $\left(1,049 \mathrm{~cm}^{-1}\right)$, carbonate group $\left(\mathrm{CO}_{3}{ }^{2} ; 1,419 \mathrm{~cm}^{-1}\right)$, bending vibration of absorbed $\mathrm{H}_{2} \mathrm{O}\left(1,641 \mathrm{~cm}^{-1}\right)$, and symmetric and asymmetric stretching of $\mathrm{O}-\mathrm{H}(3,000-3,690$ $\mathrm{cm}^{-1}$ ) [22, 38-41]. The Ca-BC before adsorption had more intensive peaks for symmetric and asymmetric stretching of $\mathrm{O}-\mathrm{H}$ than those of the raw $\mathrm{BC}$ which indicated more $\mathrm{O}-\mathrm{H}$ of $\mathrm{Ca}(\mathrm{OH})_{2}$ generated during the preparation of Ca-BC. However, The Ca-BC after adsorption had little $\mathrm{O}-\mathrm{H}$ and reduced $\mathrm{C}-\mathrm{O}$ stretching vibration because of $\mathrm{Ca}(\mathrm{OH})_{2}$-phosphate and C-O-phosphate complexation.
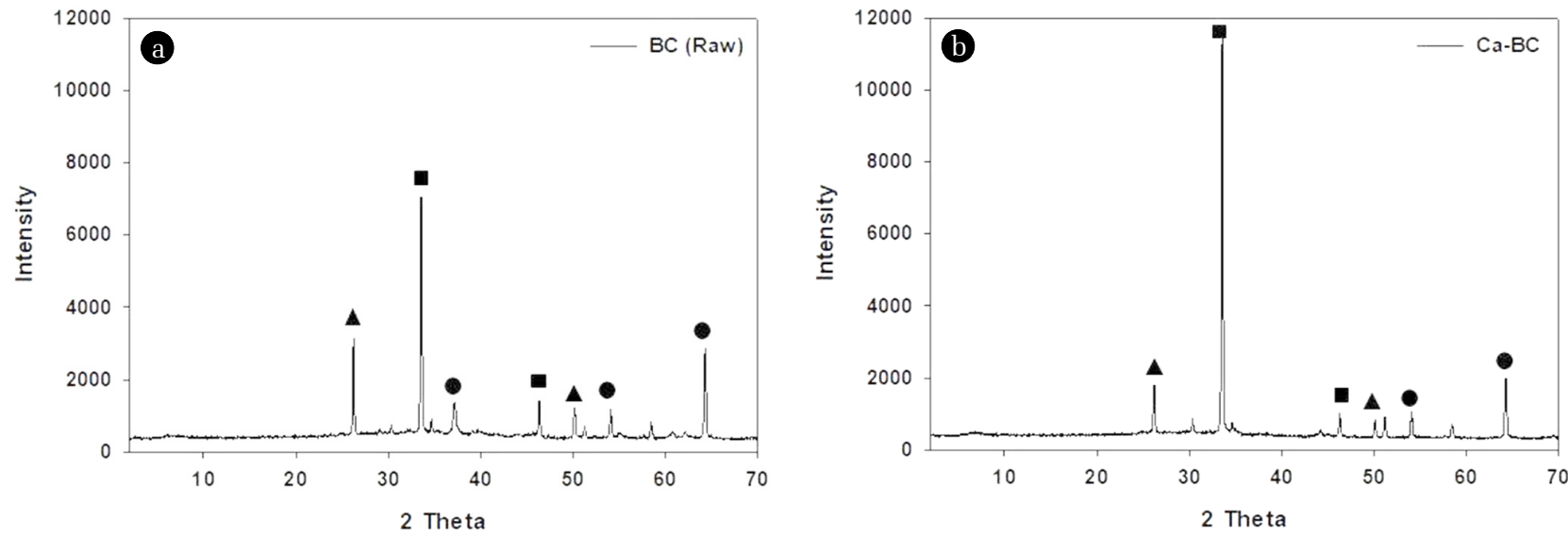

Fig. 1. XRD pattern of raw $\mathrm{BC}$ (a) and $\mathrm{Ca}-\mathrm{BC}$ (b) $\left(\mathbf{\Delta}\right.$ : $\mathrm{SiO}_{2}, \boldsymbol{\square}: \mathrm{Ca}(\mathrm{OH})_{2}$,

$\mathrm{CaO})$
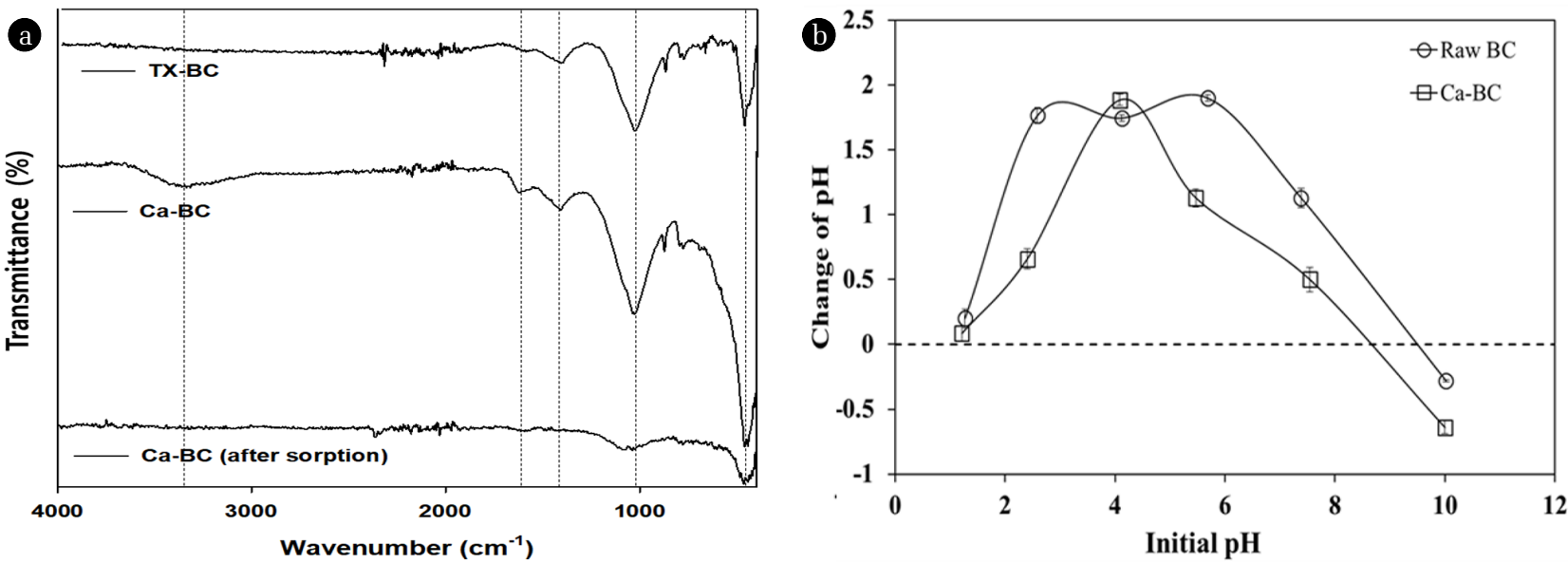

Fig. 2. FT-IR spectrum (a) and the $\mathrm{pH}$ at point of zero charge (b) of raw-BC and $\mathrm{Ca}-\mathrm{BC}$. The experiment was conducted in triplicate and error bars represent the $95 \%$ confidence interval. 
Within the $\mathrm{pH}$ range of 1.2-10, the $\mathrm{pH}$ at point of zero charge $(\mathrm{pH}, \mathrm{pzc})$ for the raw $\mathrm{BC}$ and the $\mathrm{Ca}-\mathrm{BC}$ were 9.5 and 8.7, respectively (Fig. 2(b)). It indicated the Ca-BC would be neutral or slightly positively charged at the $\mathrm{pH}$ of 8-9 (typical $\mathrm{pH}$ of lagoon effluents in dairy wastewater treatment). It would result in effective precipitation and surface deposition of phosphate onto the surface of Ca-BC rather than electrostatic interaction of phosphate and the Ca-BC.

The Ca-BC had the BET surface area $\left(2.6 \pm 0.1 \mathrm{~m}^{2} / \mathrm{g}\right)$ which was lower than that of the raw $\mathrm{BC}\left(6.3 \pm 0.5 \mathrm{~m}^{2} / \mathrm{g}\right)$ due to clogging of pores in the raw $\mathrm{BC}$ with calcium hydroxide aggregates during the coating of calcium onto the raw BC. This result was quite similar to drastic reduction of surface area in activated carbon after coating metals on activated carbon [34]. Further study would need to enhance the dispersion and deposition of calcium on biochar to prevent blockage of pores and reduction of surface area in biochar.

The elemental analysis presented that the raw BC and the Ca-BC had similar compositions of elements except higher calcium content in the Ca-BC (Fig. S2).

\subsection{Adsorption of Phosphate on Raw BC and Ca-BC}

The Ca-BC showed much higher adsorption of phosphate $(89 \%$ removal) than that by the raw $\mathrm{BC}(23 \%$ removal) as given in Fig. 3. It was thought that the $\mathrm{Ca}(\mathrm{OH})_{2}$ in the Ca-BC facilitated highly efficient surface reaction with phosphate, which was consistent with the high reactivity of phosphate and $\mathrm{Ca}(\mathrm{OH})_{2}$ in the biochar reported by Dai et al. [29]. The calcium hydroxide, $\mathrm{Ca}(\mathrm{OH})_{2}$, on the biochar would rapidly react with phosphate in water to make Ca-phosphate complexation $\left(\mathrm{Ca}_{10}\left(\mathrm{PO}_{4}\right)_{6}(\mathrm{OH})_{2}\right.$ or $\mathrm{CaHPO}_{4}$, please see Eq. (5) and (6)) [42-44].

$5 \mathrm{Ca}(\mathrm{OH})_{2}$ (s.) on the Ca-BC $+3 \mathrm{H}_{3} \mathrm{PO}_{4}$ (aq.) $\leftrightarrow$ $1 / 2 \mathrm{Ca}_{10}\left(\mathrm{PO}_{4}\right)_{6}(\mathrm{OH})_{2}$ (s.) on the Ca-BC $+9 \mathrm{H}_{2} \mathrm{O}$

$3 \mathrm{Ca}(\mathrm{OH})_{2}$ (s.) on the Ca-BC $+3 \mathrm{H}_{3} \mathrm{PO}_{4}$ (aq.) $\leftrightarrow$ $3 \mathrm{CaHPO}_{4}$ (s.) on the Ca-BC $+2 \mathrm{H}_{2} \mathrm{O}$

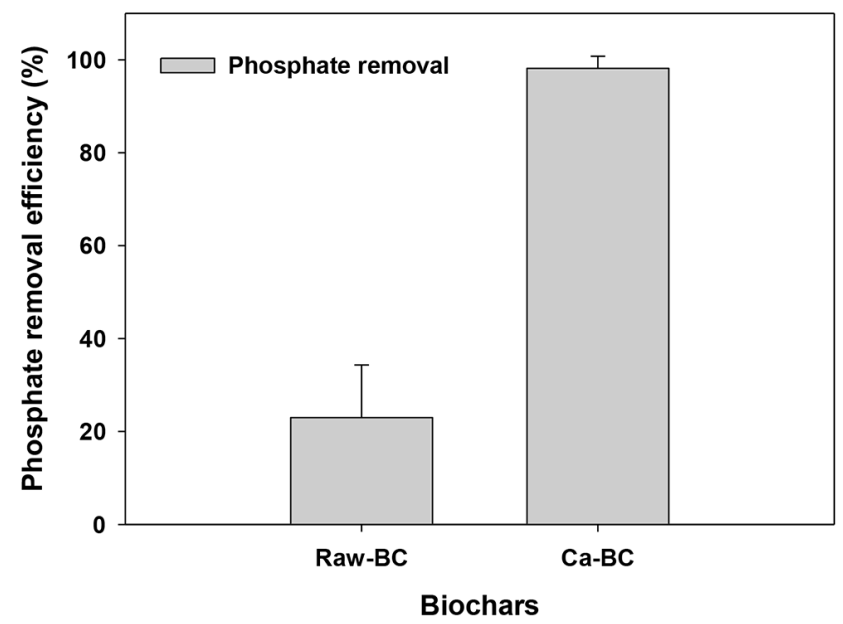

Fig. 3. Adsorption of phosphate onto raw $\mathrm{BC}$ and $\mathrm{Ca}-\mathrm{BC}$. Conditions: Initial phosphate, $30 \mathrm{mg} / \mathrm{L}, 0.02 \mathrm{~L}$; raw $\mathrm{BC}$ and Ca-BC loading, $0.1 \mathrm{~g}$; initial $\mathrm{pH}, 8.5 ; 72 \mathrm{~h}$. The experiment was conducted in triplicate and error bars represent the $95 \%$ confidence interval.
However, the raw BC led to the low adsorption of phosphate owing to lack of functional groups associated with adsorption of phosphate.

The solution $\mathrm{pH}$ influenced adsorption of phosphate on the Ca-BC in this study. Phosphate has three values of $\mathrm{p} K_{\mathrm{a}}(2.1,7.2$ and 12.7) and has differently changed functional groups at different $\mathrm{pH}$ ranges. The $\mathrm{pH}$ of phosphate solution affects adsorption in that it governs the degree of ionization in phosphate as below: [20]

$$
\begin{array}{cc}
\mathrm{H}_{3} \mathrm{PO}_{4} \rightleftharpoons \mathrm{H}^{+}+\mathrm{H}_{2} \mathrm{PO}_{4}^{-} & \mathrm{pK}_{\mathrm{a}, 1}=2.1 \\
\mathrm{H}_{2} \mathrm{PO}_{4}^{-} \rightleftharpoons \mathrm{H}^{+}+\mathrm{HPO}_{4}{ }^{2-} & \mathrm{pK}_{\mathrm{a}, 2}=7.2 \\
\mathrm{HPO}_{4}{ }^{2-} \rightleftharpoons \mathrm{H}^{+}+\mathrm{PO}_{4}{ }^{3-} & \mathrm{pK}_{\mathrm{a}, 3}=12.7
\end{array}
$$

Their predominant species are $\mathrm{H}_{3} \mathrm{PO}_{4}$ at $\mathrm{pH}<2.1, \mathrm{H}_{2} \mathrm{PO}_{4}$ at $2.1<\mathrm{pH}<7.2, \mathrm{HPO}_{4}{ }^{2-}$ at $7.2<\mathrm{pH}<12.7$, and $\mathrm{PO}_{4}{ }^{3-}$ at $\mathrm{pH}>12.7$, respectively based on the solution $\mathrm{pH}$ and $\mathrm{pK}_{\mathrm{a}}$ of phosphate in Eqs. (7)-(9). Since the $\mathrm{pH}$, pzC value of the Ca-BC was 8.7 , the surface charge of the Ca-BC was protonated (i.e., positive charge) when the solution $\mathrm{pH}$ was lower than their $\mathrm{pH}$, PZC otherwise it was the negative.

At the $\mathrm{pH}$ range (2.1-8.7), phosphate molecules $\left(\mathrm{H}_{2} \mathrm{PO}_{4}{ }^{-}\right)$have electrostatic attraction with positive charge of the Ca-BC. On the other hand, at $\mathrm{pH}$ between 8.7-12.7, phosphate molecules $\left(\mathrm{HPO}_{4}{ }^{2-}\right)$ have electrostatic repulsion with negative charge of the Ca-BC. It indicated that electrostatic attraction would serve as the main interaction between the positively charged surface of the Ca-BC and the negatively charged phosphate species at low $\mathrm{pH}$ while the precipitation and surface deposition of phosphate would serve onto the $\mathrm{Ca}$ in the biochar at high $\mathrm{pH}$. However, when adsorption of phosphate onto the Ca-BC were investigated in the initial $\mathrm{pH}$ range of 3 to 8.7 , the adsorption increased with increase of the initial solution $\mathrm{pH}$ by a factor of 2.4 (42.5\% removal at $\mathrm{pH} 3$ and $100 \%$ removal at $\mathrm{pH}$ 8.5) (Fig. 4). Therefore, the results indicated that the precipitation and surface deposition at high $\mathrm{pH}$

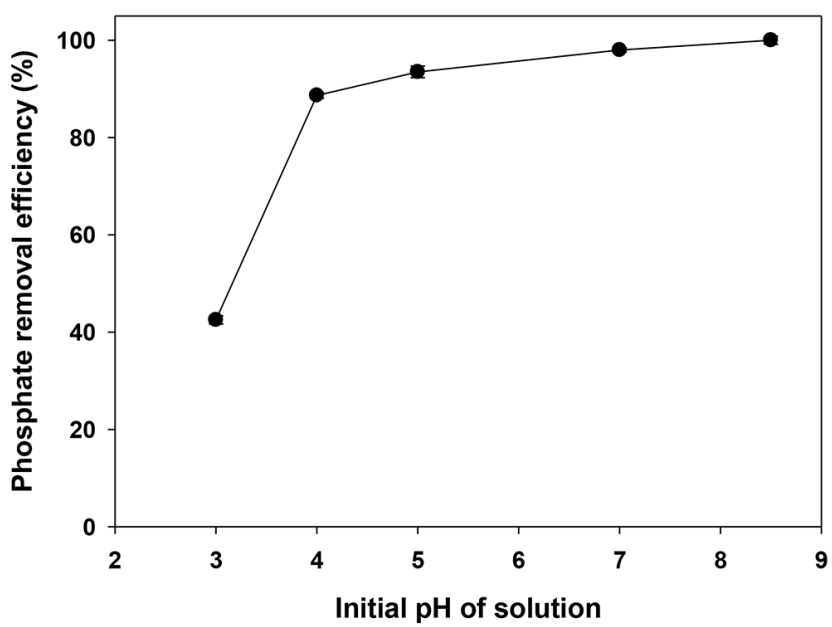

Fig. 4. Effect of $\mathrm{pH}$ on adsorption of phosphate on Ca-BC. Conditions: Initial phosphate, $30 \mathrm{mg} / \mathrm{L}, 0.02 \mathrm{~L}$; Ca-BC loading, $0.1 \mathrm{~g}$; initial $\mathrm{pH}, 8.5 ; 72 \mathrm{~h}$. The experiment was conducted in triplicate and error bars represent the $95 \%$ confidence interval. 
made significant contribution to effective adsorption of phosphate on the Ca-BC.

Similar to this result, Liu et al. [22] and Karageorgiou et al. [45] also showed that higher $\mathrm{pH}$ (i.e., 7-10) resulted in higher adsorption of phosphate on the Ca-impregnated biochar. In addition, the Ca-BC showed high adsorption of phosphate at $\mathrm{pH}$ of 8.5, which was close to the $\mathrm{pH}$ of lagoon effluents from Tarleton dairy farms. It suggests the Ca-BC would be suitable to treat the lagoon effluent from dairy farms without any adjustment of $\mathrm{pH}$, which would save the costs for chemical addition. Table S3 shows the leaching of cations from raw $\mathrm{BC}$ and $\mathrm{Ca}-\mathrm{BC}$ to water under the same conditions as the above phosphate adsorption experiments. The Ca-BC had negligible leaching of cations such as $\mathrm{Mg}, \mathrm{K}, \mathrm{Na}$ and $\mathrm{Li}$, and low leaching of $\mathrm{Ca}$. The leaching of $\mathrm{Ca}$ from the Ca-BC was approximately $3 \%$ of total $\mathrm{Ca}$ in the Ca-BC ensuring the $\mathrm{Ca}$ in the $\mathrm{Ca}-\mathrm{BC}$ was quite stable during the adsorption experiments in this study. In addition, the removal of phosphate with the cations in the leachate solution was negligible when the leachate solution was stirred with the phosphate under the same conditions as the phosphate adsorption experiments. Therefore, these results indicated that the removal of phosphate during the adsorption experiments in Fig. 3 and Fig. 4 was mainly attributed to the adsorption of phosphate on the calcium hydroxide on Ca-BC.

\subsection{Isotherms and Kinetics Analysis for Adsorption of Phosphate onto the Ca-BC}

Freundlich, Langmuir and Temkin models have been used for describing adsorption phenomena in aqueous solutions [46]. Based on the $\mathrm{R}^{2}$, SSE and $\chi^{2}$, the Freundlich model $\left(\mathrm{R}^{2}=0.997\right.$, SSE $\left.=0.171, \chi^{2}=0.043\right)$ was the better-fitted one than Langmuir $\left(\mathrm{R}^{2}=0.945\right.$, SSE $\left.=1.623, \chi^{2}=0.823\right)$ and Temkin $\left(\mathrm{R}^{2}=0.975\right.$, $\mathrm{SSE}=0.548, \chi^{2}=0.472$ ) models for adsorption of phosphate onto the Ca-BC (Fig. 5) [37]. The result indicates multi-layer adsorption of phosphate onto the Ca-BC. The isotherm parameters of Freundlich and Langmuir models for adsorption of phosphate on the Ca-BC at $20^{\circ} \mathrm{C}$ are summarized in Fig. 5. The maximum adsorption capacity of the Ca-BC $\left(\mathrm{q}_{\mathrm{m}}=13.61 \mathrm{mg} / \mathrm{g}\right)$ was higher than those with iron oxide and zinc-coated plant-derived biochars (3-5 mg phosphate/g biochar) [26-28], while it was lower than those with $\mathrm{CaO}$ - and $\mathrm{MgO}-$-coated biochars derived from plants (105-110 mg phosphate/g biochar) [22, 25], as summarized in Table 1. However, considering the Ca-BC was prepared via wet impregnation of calcium onto biochar at ambient temperature, application of the Ca-BC for adsorption of phosphate was found to be more economical than those using the $\mathrm{CaO}$ - and calcite-coated biochars via pyrolysis or calcination at $500-900^{\circ} \mathrm{C}[22,29]$. In addition, by counting on the phosphate adsorption capacity per surface area of biochar, the Ca-BC in this study showed the phosphate adsorption capacity (4.9 mg phosphate $/ \mathrm{m}^{2}$ biochar) which was comparable to those of $\mathrm{CaO}-$ biochar and (Al-Mg)-coated biochar (5.3-7 mg phosphate $/ \mathrm{m}^{2}$ biochar) and higher than those of iron oxide- and MgO-coated plant biochars (0.06-0.6 mg phosphate $/ \mathrm{m}^{2}$ biochar, Table 1). It indicates that the surface of the Ca-BC coated with calcium hydroxide in this study possessed high reactivity to enhance adsorption capacity of phosphate in water.
In order to understand the mechanism of adsorption process, pseudo-first order, pseudo-second order, and Elovich models have been used for kinetics of phosphate adsorption. Various studies reported the adsorption of phosphate onto metal-coated biochar followed either pseudo-first order or pseudo-second order kinetic model $[22,25,30]$. However, the phosphate adsorption by Ca-BC was found to follow pseudo-second order kinetic (Fig. 6) in this study. As shown in Table S4, the pseudo-second order kinetic model was the best fitted one with highest $\mathrm{R}^{2}$ (0.974), lowest sum of squared error (SSE, 0.307) and lowest $\chi^{2}$ (0.377). It suggested that chemisorptive interactions would be more dominant than physisorption [44, 47]. Besides, the O-H peak in the Ca-BC was

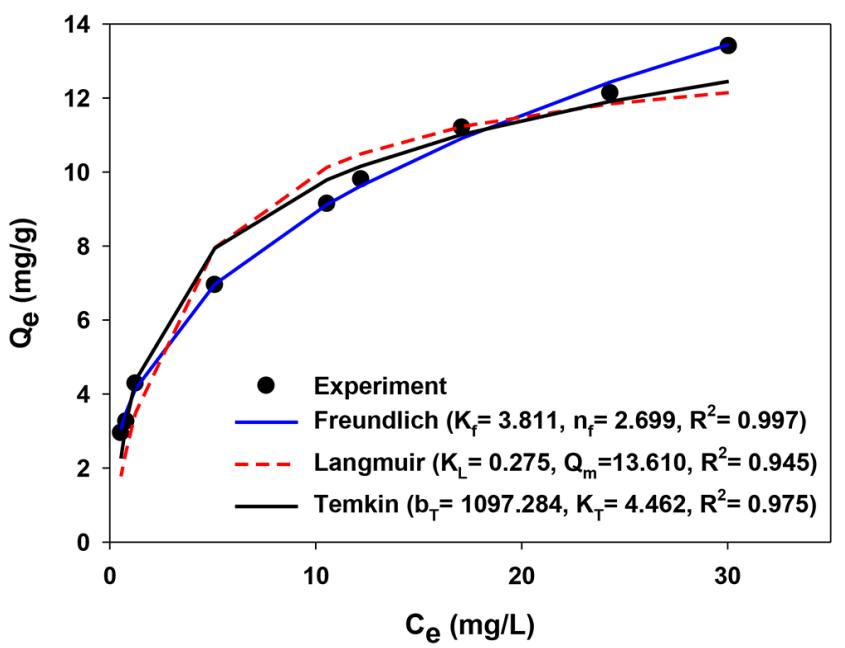

Fig. 5. Nonlinear analysis for adsorption isotherm of phosphate onto Ca-BC. Conditions for the experiments: initial phosphate, 30 $\mathrm{mg} / \mathrm{L}, 0.02 \mathrm{~L}$; initial $\mathrm{pH}, 8.5 ; 72$ h. Qe: the amount of phosphate adsorbed per unit mass of adsorbent at equilibrium (mg/g). $\mathrm{C}_{\mathrm{e}}$ : the liquid-phase concentration of phosphate at equilibrium (mg/L).

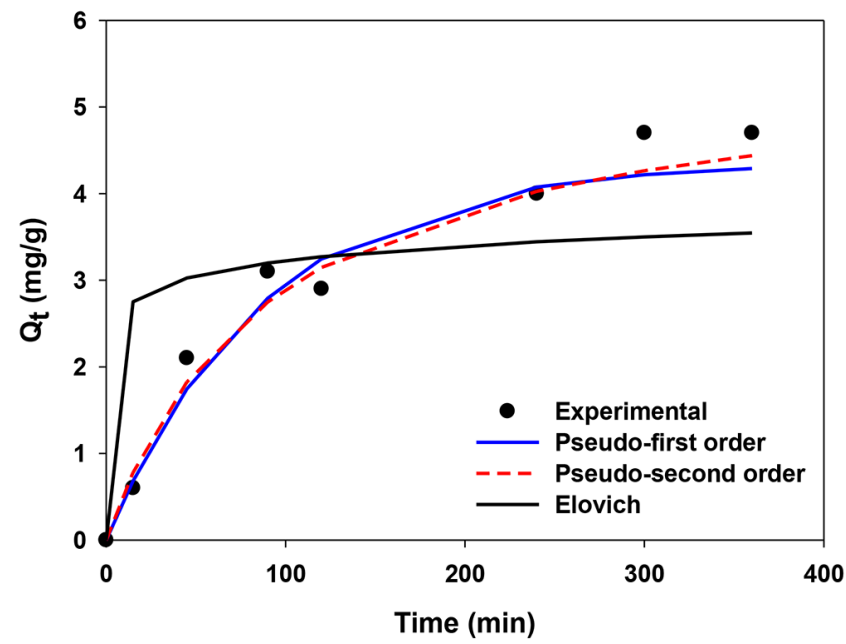

Fig. 6. Adsorption kinetic of phosphate onto Ca-BC by fitting the pseudo-first order, pseudo-second order, and Elovich. Conditions for the experiments: initial phosphate, $30 \mathrm{mg} / \mathrm{L}, 0.02 \mathrm{~L}$; initial $\mathrm{pH}$, 8.5; 72 h. Qt: an adsorption capacity (mg/g) at time t (min). 
significantly reduced after adsorption of phosphate (please see the FT-IR results in Fig. 2(a)). The reduction of O-H groups in the Ca-BC after adsorption of phosphate could support the chemical precipitation of phosphate with $\mathrm{Ca}(\mathrm{OH})_{2}$. However, thermodynamic analysis of adsorption and additional instrumental characterization (i.e., XPS, C-NMR) will help to understand more detailed mechanisms associated with adsorption of phosphate onto the Ca-BC.

\subsection{Adsorption of Phosphate from Real Dairy Wastewater onto $\mathrm{Ca}-\mathrm{BC}$}

The lagoon effluents from Tarleton dairy farm (Stephenville, Texas) were mixed with the Ca-BC in the glass flasks to assess the adsorption of phosphate and other contaminants such as COD and total nitrogen. The Tarleton dairy farm operates approximately 400 dairy cows and the dairy wastewater is treated by two lagoons as dairy manure is flushed by water into the lagoons. The lagoon effluents contained COD at 1,571 ppm, total nitrogen at $168 \mathrm{ppm}$ and total phosphate at $45 \mathrm{ppm}$. The detailed characteristics of lagoon effluents are listed in Table S5.

The Ca-BC showed significant adsorption of phosphate from the dairy lagoon effluents (Fig. 7). The effective adsorption of phosphate in the lagoon effluents onto the Ca-BC was thought to be mainly due to strong interaction between calcium hydroxide, calcium oxide and phosphate as reported from others' studies $[22,29,30]$. The moderate adsorption of COD onto the Ca-BC indicated the organic contaminants in the lagoon effluents would be further removed by the Ca-BC due to hydrophobic and $\pi-\pi$ interactions between organic contaminants and the carbon site of Ca-BC. However, there was poor adsorption of ammonium in the wastewater onto the $\mathrm{Ca}-\mathrm{BC}$ due to the electrostatic repulsion between the surface in the Ca-BC and ammonium in the wastewater at $\mathrm{pH}$ of lagoon effluent (8.5 in this study).

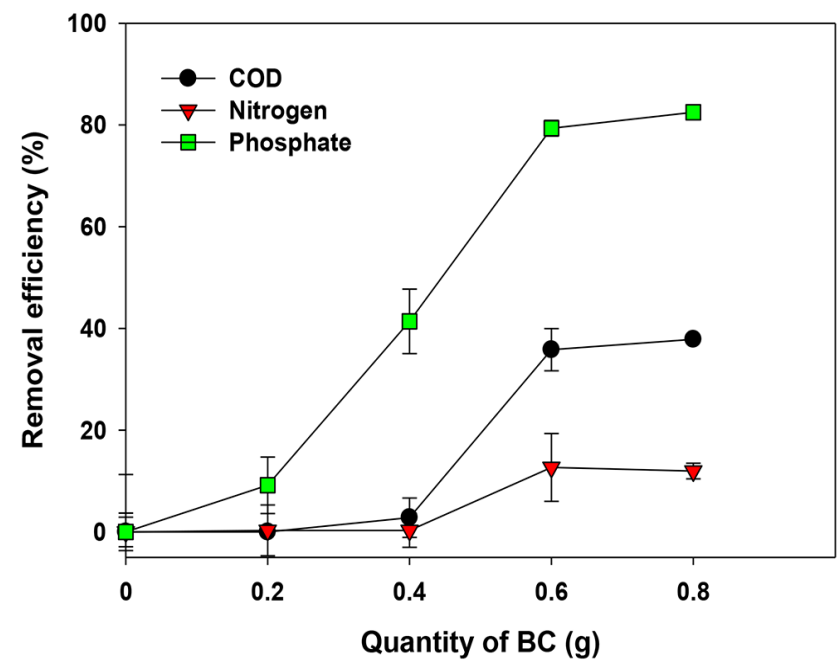

Fig. 7. Application of $\mathrm{Ca}-\mathrm{BC}$ for treatment of dairy lagoon effluents. Conditions: Initial quality of dairy effluents (Initial pH, 8.5; COD, $1,571 \mathrm{mg} / \mathrm{L}$; total $\mathrm{N}, 168 \mathrm{mg} / \mathrm{L}$; total $\mathrm{P}, 45 \mathrm{mg} / \mathrm{L}) ; 0.02 \mathrm{~L}$ of dairy effluent, $72 \mathrm{~h}$. The experiment was conducted in triplicate and error bars represent the $95 \%$ confidence interval.
However, the adsorption of phosphate in the lagoon effluent onto the Ca-BC was found to be lower than that in the DI water at the same conditions (Fig. S3). This would be explained that multiple anions (i.e., sulfate, carbonate, chloride, nitrate) abundant in the lagoon effluent could compete with phosphate for the adsorption onto the surface of Ca-BC as reported by Mazloomi and Jalali [48] and Constantino et al. [49]. The lagoon effluent used for the adsorption of phosphate in this work possessed $12.8 \mathrm{ppm}$ of sulfate, $68.65 \mathrm{ppm}$ of chloride, $1.57 \mathrm{ppm}$ of fluoride and 8.51 ppm of nitrate. This result supports that various anions interfered the adsorption of phosphate in real wastewater. Further works will include detailed investigation for effects of multiple anions in dairy effluent on adsorption of phosphate onto the Ca-BC.

\section{Conclusions}

The Ca-BC was prepared via wet impregnation of calcium onto the raw $\mathrm{BC}$ under ambient conditions. The characterization of Ca-BC showed abundant calcium (mostly calcium hydroxide) attached onto the surface of biochar with limited surface area and various functional groups associated with calcium and phosphate. The Ca-BC revealed much higher adsorption of phosphate than that of raw $\mathrm{BC}$ due to high reactive interactions between calcium hydroxide and phosphate. Pseudo second-order kinetic and Freundlich isotherm models revealed the best fitted ones for the adsorption of phosphate onto Ca-BC indicating chemisorptive interaction occurred on surface of Ca-BC. The maximum adsorption capacity of Ca-BC reached $13.6 \mathrm{mg} / \mathrm{g}$, which was higher than those of iron oxide and zinc oxide-coated plant-derived biochars, but lower than those of $\mathrm{CaO}$ - and $\mathrm{MgO}$-coated plant-derived biochars. However, the Ca-BC showed high reactivity per surface area for adsorption of phosphate indicating importance of surface functionalization of biochar. While the Ca-BC led to higher adsorption of phosphate in the dairy wastewater with the increasing loading of biochar, its adsorption performance was found to be lower than that for phosphate in a DI water probably owing to competition of other anions (i.e., sulfate, carbonate, chloride) in wastewater with phosphate.

\section{Acknowledgments}

This work was supported by Texas A\&M University Chancellor Research Initiative Fund. The authors also thank Professor Sergio Capareda at Texas A\&M University for providing the biochar.

\section{References}

1. Cieślik B, Konieczka P. A review of phosphorus recovery methods at various steps of wastewater treatment and sewage sludge management. The concept of "no solid waste generation" and analytical methods. J. Clean. Prod. 2017;142:1728-1740.

2. Li R, Wang JJ, Zhou B, et al. Recovery of phosphate from aqueous solution by magnesium oxide decorated magnetic biochar and its potential as phosphate-based fertilizer 
substitute. Bioresour. Technol. 2016;215:209-214.

3. Shepherd JG, Sohi SP, Heal KV. Optimising the recovery and re-use of phosphorus from wastewater effluent for sustainable fertiliser development. Water Res. 2016;94:155-165.

4. Shih Y-J, Abarca RRM, de Luna MDG, Huang Y-H, Lu M-C. Recovery of phosphorus from synthetic wastewaters by struvite crystallization in a fluidized-bed reactor: Effects of ph, phosphate concentration and coexisting ions. Chemosphere 2017;173:466-473.

5. McDowell RW, Sharpley AN. Approximating phosphorus release from soils to surface runoff and subsurface drainage. J. Environ. Qual. 2001;30:508-520.

6. Yu P, Xue Y, Gao F, Liu Z, Cheng X, Yang K. Phosphorus removal from aqueous solution by pre- or post-modified biochars derived from agricultural residues. Water Air Soil Pollut. 2016;227:370.

7. Chan C, Guisasola A, Baeza JA. Enhanced biological phosphorus removal at low sludge retention time in view of its integration in A-stage systems. Water Res. 2017;118:217-226.

8. Li Z, Sun X, Huang L, et al. Phosphate adsorption and precipitation on calcite under calco-carbonic equilibrium condition. Chemosphere 2017;183:419-428.

9. Tran N, Drogui P, Blais J-F, Mercier G. Phosphorus removal from spiked municipal wastewater using either electrochemical coagulation or chemical coagulation as tertiary treatment. Sep. Purif. Technol. 2012;95:16-25.

10. Park H-S, Kwak S-H, Mahardika D, Mameda N, Choo K-H. Mixed metal oxide coated polymer beads for enhanced phosphorus removal from membrane bioreactor effluents. Chem. Eng. J. 2017;319:240-247.

11. Zhu N, Yan T, Qiao J, Cao H. Adsorption of arsenic, phosphorus and chromium by bismuth impregnated biochar: Adsorption mechanism and depleted adsorbent utilization. Chemosphere 2016;164:32-40.

12. Yao Y, Gao B, Inyang M, et al. Biochar derived from anaerobically digested sugar beet tailings: Characterization and phosphate removal potential. Bioresour. Technol. 2011;102:6273-6278.

13. Zhang M, Gao B, Yao Y, Xue Y, Inyang M. Synthesis of porous MgO-biochar nanocomposites for removal of phosphate and nitrate from aqueous solutions. Chem. Eng. J. 2012;210:26-32.

14. Yao Y, Gao B, Chen J, Yang L. Engineered biochar reclaiming phosphate from aqueous solutions: Mechanisms and potential application as a slow-release fertilizer. Environ. Sci. Technol. 2013;47:8700-8708.

15. Ahmad M, Rajapaksha AU, Lim JE, et al. Biochar as a sorbent for contaminant management in soil and water: A review. Chemosphere 2014;99:19-33.

16. Ahmed MB, Zhou JL, Ngo HH, Guo W, Chen M. Progress in the preparation and application of modified biochar for improved contaminant removal from water and wastewater. Bioresour. Technol. 2016;214:836-851.

17. Ghezzehei T, Sarkhot D, Berhe A. Biochar can be used to capture essential nutrients from dairy wastewater and improve soil physico-chemical properties. Solid Earth 2014;5:953.

18. Hale SE, Alling V, Martinsen V, Mulder J, Breedveld GD, Cornelissen G. The sorption and desorption of phosphate-P, ammonium-N and nitrate- $\mathrm{N}$ in cacao shell and corn cob biochars. Chemosphere 2013;91:1612-1619.

19. Cui X, Hao H, He Z, Stoffella PJ, Yang X. Pyrolysis of wetland biomass waste: Potential for carbon sequestration and water remediation. J. Environ. Manage. 2016;173:95-104.

20. Yao Y, Gao B, Inyang M, et al. Removal of phosphate from aqueous solution by biochar derived from anaerobically digested sugar beet tailings. J. Hazard. Mater. 2011;190:501-507.

21. Wan S, Wang S, Li Y, Gao B. Functionalizing biochar with $\mathrm{Mg}-\mathrm{Al}$ and $\mathrm{Mg}-\mathrm{Fe}$ layered double hydroxides for removal of phosphate from aqueous solutions. J. Ind. Eng. Chem. 2017;47:246-253.

22. Liu S-b, Tan X-f, Liu Y-g, et al. Production of biochars from Ca impregnated ramie biomass (Boehmeria nivea (L) Gaud.) and their phosphate removal potential. RSC $A d v$. 2016;6: 5871-5880.

23. Chen B, Chen Z, Lv S. A novel magnetic biochar efficiently sorbs organic pollutants and phosphate. Bioresour. Technol. 2011;102:716-723.

24. Chen L, Chen XL, Zhou CH, et al. Environmental-friendly montmorillonite-biochar composites: Facile production and tunable adsorption-release of ammonium and phosphate. $J$. Clean. Prod. 2017;156:648-659.

25. Gong Y-P, Ni Z-Y, Xiong Z-Z, Cheng L-H, Xu X-H. Phosphate and ammonium adsorption of the modified biochar based on phragmites australis after phytoremediation. Environ. Sci. Pollut. Res. 2017;24:8326-8335.

26. Micháleková-Richveisová B, Frišták V, Pipíška M, Ďuriška L, Moreno-Jimenez E, Soja G. Iron-impregnated biochars as effective phosphate sorption materials. Environ. Sci. Pollut. Res. 2017;24:463-475.

27. Namasivayam C, Sangeetha D. Equilibrium and kinetic studies of adsorption of phosphate onto $\mathrm{ZnCl}_{2}$ activated coir pith carbon. J. Colloid Interface Sci. 2004;280:359-365.

28. Ramola S, Mishra T, Rana G, Srivastava RK. Characterization and pollutant removal efficiency of biochar derived from baggase, bamboo and tyre. Environ. Monit. Assess. 2014;186: 9023-9039.

29. Dai L, Tan F, Li H, et al. Calcium-rich biochar from the pyrolysis of crab shell for phosphorus removal. J. Environ. Manage. 2017;198(Pt 1):70-74.

30. Fang C, Zhang T, Li P, et al. Phosphorus recovery from biogas fermentation liquid by Ca-Mg loaded biochar. J. Environ. Sci. 2015;29:106-114.

31. Cao X, Ma L, Liang Y, Gao B, Harris W. Simultaneous immobilization of lead and atrazine in contaminated soils using dairy-manure biochar. Environ. Sci. Technol. 2011;45:4884-4889.

32. Xu X, Cao X, Zhao L, Wang H, Yu H, Gao B. Removal of $\mathrm{Cu}, \mathrm{Zn}$, and $\mathrm{Cd}$ from aqueous solutions by the dairy manure-derived biochar. Environ. Sci. Pollut. Res. 2013;20:358-368.

33. Nam H, Maglinao Jr AL, Capareda SC, Rodriguez-Alejandro DA. Enriched-air fluidized bed gasification using bench and pilot scale reactors of dairy manure with sand bedding based on response surface methods. Energy 2016;95:187-199.

34. Kan E, Huling SG. Effects of temperature and acidic pre-treatment on Fenton-driven oxidation of MTBE-spent granular activated carbon. Environ. Sci. Technol. 2009;43:1493-1499.

35. Samsuri AW, Sadegh-Zadeh F, Seh-Bardan BJ. Adsorption 
of $\mathrm{As}(\mathrm{III})$ and $\mathrm{As}(\mathrm{V})$ by Fe coated biochars and biochars produced from empty fruit bunch and rice husk. J. Environ. Chem. Eng. 2013;1:981-988.

36. Tan WF, Lu SJ, Liu F, Feng XH, He JZ, Koopal LK. Determination of the point-of-zero charge of manganese oxides with different methods including an improved salt titration method. Soil Sci. 2008;173:277-286.

37. Ho Y-S, Chiu W-T, Wang C-C. Regression analysis for the sorption isotherms of basic dyes on sugarcane dust. Bioresour. Technol. 2005;96:1285-1291.

38. Choudhary R, Koppala S, Swamiappan S. Bioactivity studies of calcium magnesium silicate prepared from eggshell waste by sol-gel combustion synthesis. J. Asian Ceram. Soc. 2015;3:173-177.

39. Asikin-Mijan N, Taufiq-Yap Y, Lee H. Synthesis of clamshell derived $\mathrm{Ca}(\mathrm{OH})_{2}$ nano-particles via simple surfactant-hydration treatment. Chem. Eng. J. 2015;262:1043-1051.

40. Trezza MA. Hydration study of ordinary portland cement in the presence of zinc ions. Mater. Res. 2007;10:331-334.

41. Han L, Qian L, Liu R, Chen M, Yan J, Hu Q. Lead adsorption by biochar under the elevated competition of cadmium and aluminum. Sci. Rep. 2017;7:2264.

42. Kim W, Saito F. Sonochemical synthesis of hydroxyapatite from $\mathrm{H}_{3} \mathrm{PO}_{4}$ solution with $\mathrm{Ca}(\mathrm{OH})_{2}$. Ultrason. Sonochem. 2001;8:85-88.
43. Hosni K, Moussa SB, Chachi A, Amor MB. The removal of $\mathrm{PO}_{4}{ }^{3-}$ by calcium hydroxide from synthetic wastewater: Optimisation of the operating conditions. Desalination 2008;223:337-343.

44. Wang S, Kong L, Long J, et al. Adsorption of phosphorus by calcium-flour biochar: Isotherm, kinetic and transformation studies. Chemosphere 2018;195:666-672.

45. Karageorgiou K, Paschalis M, Anastassakis GN. Removal of phosphate species from solution by adsorption onto calcite used as natural adsorbent. J. Hazard. Mater. 2007;139:447-452.

46. Han J, Qiu W, Cao Z, Hu J, Gao W. Adsorption of ethinylestradiol (EE2) on polyamide 612: Molecular modeling and effects of water chemistry. Water Res. 2013;47:2273-2284.

47. Kim JR, Huling SG, Kan E. Effects of temperature on adsorption and oxidative degradation of bisphenol a in an acid-treated iron-amended granular activated carbon. Chem. Eng. J. 2015;262:1260-1267.

48. Mazloomi F, Jalali M. Adsorption of ammonium from simulated wastewater by montmorillonite nanoclay and natural vermiculite: Experimental study and simulation. Environ. Monit. Assess. 2017;189:415.

49. Constantino LV, Quirino JN, Monteiro AM, et al. Sorption-desorption of selenite and selenate on $\mathrm{Mg}$-Al layered double hydroxide in competition with nitrate, sulfate and phosphate. Chemosphere 2017;181:627-634. 